\title{
Assessing the Early Marine Ecology of Juvenile Chinook Salmon in a Warming Bering Sea
}

\author{
Kathrine G. Howard ${ }^{1}$, Sabrina Garcia ${ }^{1}$, and James Murphy ${ }^{2}$ \\ ${ }^{1}$ Alaska Department of Fish and Game, Division of Commercial Fisheries, 333 Raspberry Road, Anchorage, AK \\ 99517, USA \\ ${ }^{2}$ NOAA Fisheries, Alaska Fisheries Science Center, Ted Stevens Marine Research Institute, Auke Bay Laboratories, \\ 17109 Point Lena Loop Road, Juneau, Alaska, 99801, USA
}

Keywords: Chinook salmon, Oncorhynchus tshawytscha, Yukon River, juvenile abundance, marine, adult forecasting, climate

Yukon River Chinook salmon (Oncorhynchus tshawytscha) returns have declined dramatically since the late 1990s, leading to severely restricted subsistence harvests and closures of commercial and sport fisheries in attempts to meet spawning escapement needs (Estensen et al. 2015). Despite extraordinary harvest reductions, pervasive failures to meet escapement objectives in the Yukon River and other Alaskan systems have occurred throughout recent years (Munro and Volk 2014). Although causes of this production decline are unclear, concurrent declines throughout Alaska (ADF\&G 2013) have placed emphasis on ocean conditions and the marine life history stage of Chinook salmon.

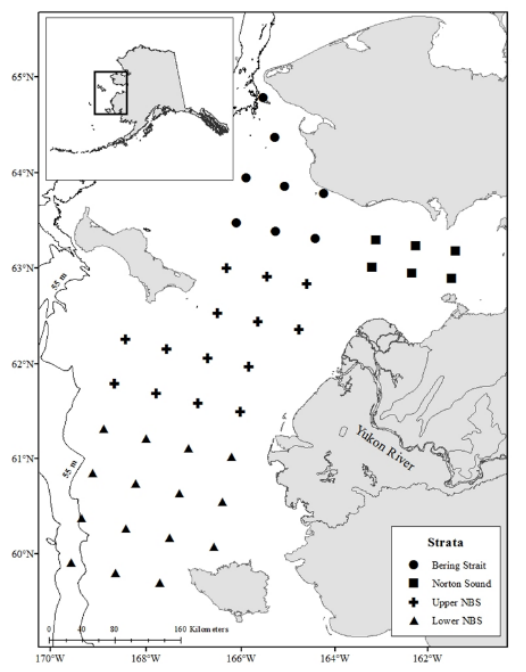

Fig. 1. Northeastern Bering Sea survey stations with symbols representing each of four spatial strata.

The northeastern Bering Sea (NBS) is the primary rearing habitat of Yukon River juvenile Chinook salmon during their first summer at sea (Murphy et al. 2009). NBS pelagic trawl surveys were initiated in 2002 and have continued through 2018. NBS surveys use a pelagic trawl net modified to fish at the surface to collect fish samples, principally juvenile salmon, using a systematic spatial sampling design (Fig. 1; Murphy et al. 2017). The NBS surveys have occurred primarily in September, assessing juvenile salmon well after they experience a critical transition from freshwater to marine environments (Farley et al. 2007).

Survey catch and oceanographic data have been used to estimate juvenile Chinook salmon abundance in the NBS. The NBS survey grid is subdivided into four strata: 1) Lower NBS $\left.\left(60^{\circ} \mathrm{N}-62^{\circ} \mathrm{N}\right), 2\right)$ Upper NBS $\left(62^{\circ} \mathrm{N}-\right.$ $\left.64^{\circ} \mathrm{N}\right), 3$ ) Norton Sound, and 4) the Bering Strait (Murphy et al. 2017; Howard et al. 2019). Within each stratum, juvenile Chinook salmon catch was expanded by a mixed layer depth (MLD) correction. Juvenile salmon were assumed to be uniformly distributed throughout the mixed water layer (depth of upper portion of water column of uniform density); however, because trawl gear does not sample through the entire mixed layer at all stations, a correction was applied to the juvenile Chinook salmon catch to account for the proportion of the mixed layer not trawled. Catch per unit area (CPUA, \#/ $\mathrm{km}^{2}$ ) was calculated for each stratum, weighted by stratum area, and summed across strata to estimate an overall CPUA for the NBS. Total juvenile abundance was estimated by multiplying the overall CPUA by the total NBS survey area (Murphy et al. 2017; Howard et al. in press).

Genetic tissues samples were collected from all juvenile Chinook salmon caught during NBS surveys to estimate stock composition and stock-specific juvenile abundance. Stock composition was estimated by comparing 
genotypes of catch samples with reference baseline allele frequencies using the Bayesian statistical approach implemented in the software package BAYES with a flat prior (Pella and Masuda 2001). Juvenile Chinook salmon stock composition from four reporting groups was estimated: 3 Yukon River stock groups (Lower Yukon, Middle Yukon, Canadian Yukon), and Other Western Alaska (Howard et al. 2019). Between 2003 and 2018, Yukon Riverorigin Chinook salmon have comprised between $72 \%$ and $96 \%$ of the total juvenile Chinook salmon catch from NBS surveys (Fig. 2). Stock-specific juvenile abundance was the product of the juvenile Chinook salmon abundance and the genetic stock proportion of that stock group (e.g., total Yukon).

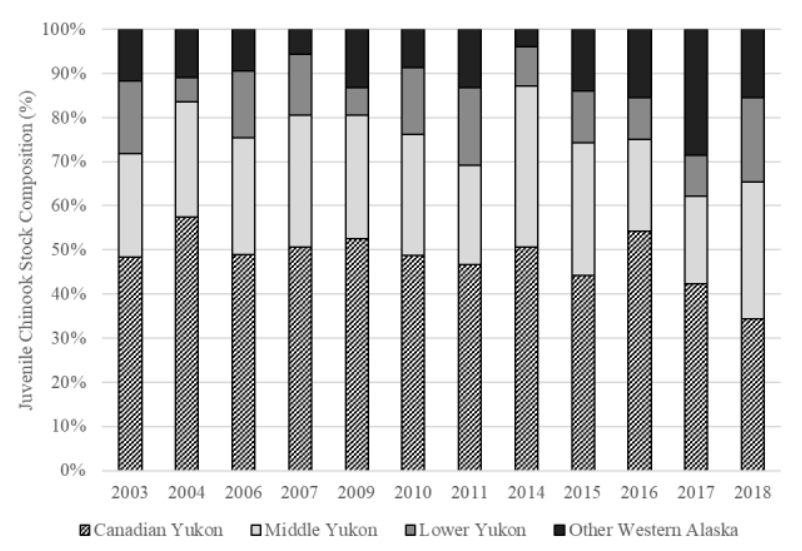

Fig. 2. Relative proportional stock composition of juvenile Chinook salmon in the northeastern Bering Sea surveys in 2003-2018, inadequate or no samples available in 2005, 2008, 2012 and 2013.

Total Yukon juvenile abundance estimates from the NBS were used to forecast adult Chinook salmon runs to the Yukon River (Murphy et al. 2017; Howard et al. in press). The projected range of adult survivors for each juvenile cohort was estimated by the $80 \%$ prediction interval of a linear regression model of total Yukon River juvenile and adult abundance (2003-2013 juvenile years, Fig. 3). Projected survivors were apportioned to run year based on recent 3-year average maturity schedules (Howard et al. in press). Juvenile abundance estimates from the NBS can be used to forecast adult run sizes up to 3 years in the future because Yukon River Chinook salmon primarily emigrate to sea at 2 years old (stream-type) and primarily return to spawn as age- 5 and age- 6 fish.

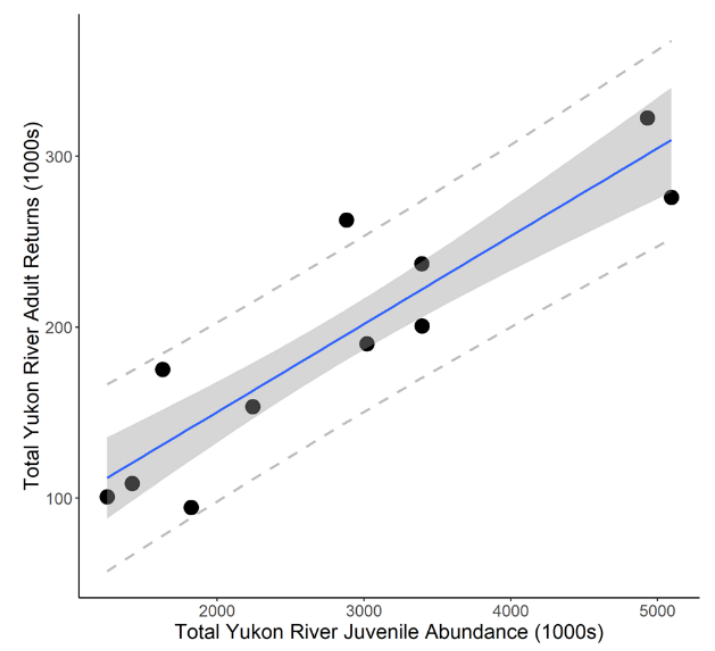

Fig. 3. Cohort relationships of northeastern Bering Sea juvenile Chinook salmon abundance and adult returns (black circles) for total Yukon River stock groups. The linear model fit is represented by the solid line $\left(R^{2}=0.80, \mathrm{~F}(1,9)=36.57, p<0.001\right), 80 \%$ confidence interval of the linear model is represented by the shaded area, and the $80 \%$ prediction interval is represented by the dashed lines.

Adult run forecasts to the Yukon River have been provided to fishery managers and stakeholders since 2013 (Fig. 4). From 2013-2017, adult Chinook salmon runs fell within the forecasted range based on NBS juvenile Chinook salmon abundance whereas the 2018 run size fell outside the forecasted range. Discussions with managers and stakeholders indicated that the trade-off between forecast accuracy and forecast precision (width of a forecast range) was such that wider ranges than those provided by the $80 \%$ prediction interval were deemed less useful for decision-making. Juvenile Chinook salmon data from the NBS through 2018 contributes to forecasts for 2020-2022 (adults return at age-4, age-5, and age-6). Based on the most recent juvenile abundance data, fishery managers and stakeholders should expect decreasing Chinook salmon run sizes to the Yukon River over the next 3 years. These predicted Chinook salmon run sizes have the potential to meet escapement objectives and provide for some subsistence harvest opportunity but are unlikely to support significant additional harvest opportunities. It should be 
noted that interannual variability in the proportions maturing at each age class can potentially introduce considerable error in forecast estimates. A more nuanced predictor of maturity beyond the recent 3-year average could enhance the development of the forecast.

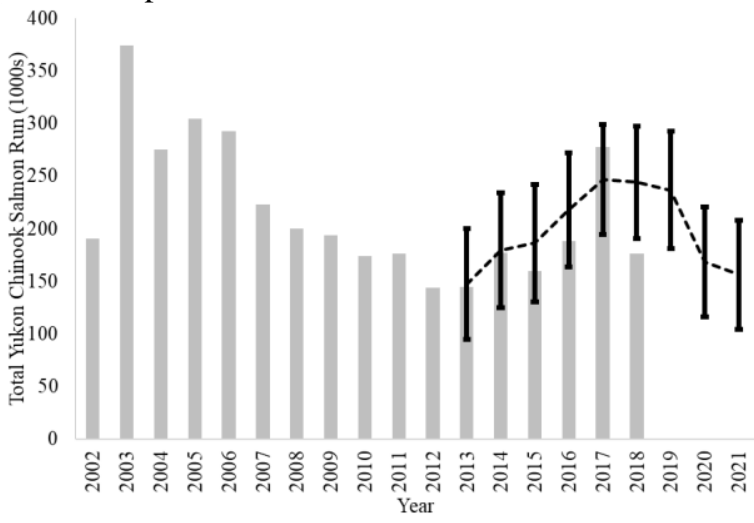

Fig. 4. Adult run size of total Yukon River Chinook salmon stock groups (grey bars) and projected run size based on northeastern Bering Sea juvenile abundance forecast (black dashed line and error bars indicating forecast range).

In addition to providing forecasts of adult run abundance, NBS surveys have played an important role in our understanding of the early marine ecology of juvenile Yukon River Chinook salmon. Results from the NBS surveys have shown that mean marine survival from September of the first year in the ocean to adulthood is low and typically remains between 5\%-8\% for total Yukon Chinook salmon (Howard et al. in press). While there is no evident relationship between the number of Yukon River adult spawners and total Yukon juvenile abundance resulting from those spawning events (Fig. 5), there is a strong, positive relationship between total Yukon juvenile abundance and total Yukon adult returns. Taken together, these results suggest that juvenile cohort strength is defined by September of their first year in the ocean (Fig. 3). These results are not unexpected as the early marine stage is believed to be a critical time for juvenile salmon (Hartt 1980; Pearcy 1992; Beamish and Mahnken 2001; Farley et al. 2007). However, these results indicate the first winter at sea may be less influential to cohort strength for this stock than factors occurring earlier in their marine (or possibly freshwater) life history.

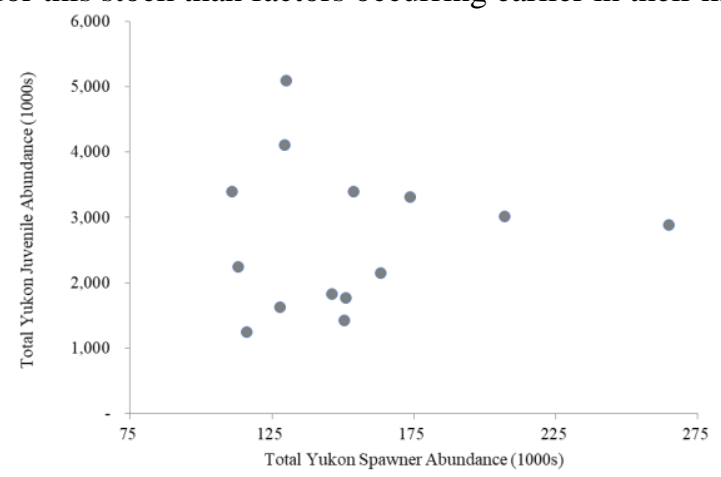

Fig. 5. Lack of relationship between the number of total Yukon River Chinook salmon spawners and the total juvenile abundance produced from those spawning events indicates the number of spawners is a poor predictor of juvenile cohort strength or future brood returns.

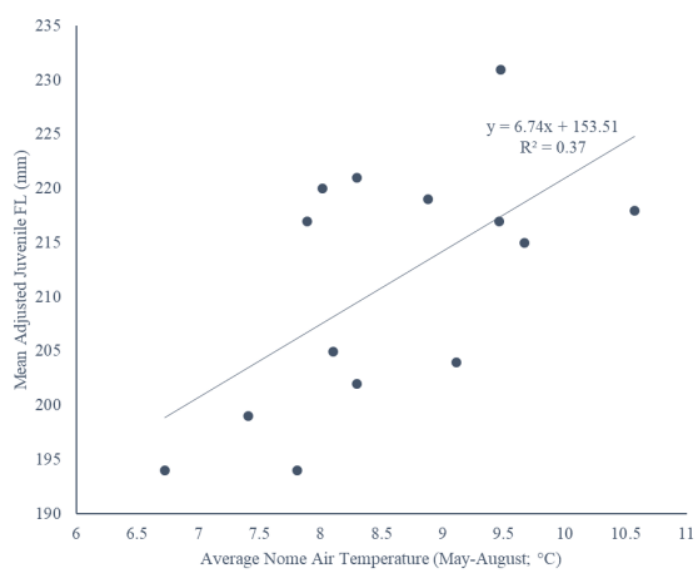

Fig. 6. Mean summer air temperature in Nome (Norton Sound) preceding juvenile capture in northeastern Bering Sea surveys and mean adjusted fork length of juvenile Chinook salmon sampled on surveys. 
In river smolt and early marine juvenile data reveal important changes associated with warmer temperatures. An outmigration study in the Yukon River found that Chinook and chum salmon smolts entered the marine environment earlier as spring air temperature increased, and river ice break up occurred earlier (Howard et al. 2019). Warmer spring/summer air temperatures also correlated with larger juvenile Chinook salmon captured during NBS surveys in September (Fig. 6). A higher proportion of Chinook salmon maturing as age-3 and age-4 ("jack") fish was associated with those juvenile cohorts that were larger on average when measured during September NBS surveys (Fig. 7), supporting other research that suggests higher early marine growth may be associated with earlier age at maturation (Siegel et al. 2017). Juvenile Chinook salmon diet and condition was also influenced by warmer temperatures. In warm years juvenile Chinook salmon marine diet consisted of sand lance (Ammodytes spp.) and decapods whereas in colder years diet contained higher proportions of capelin (Mallotus villosus). Energy density of juvenile Chinook salmon muscle tissue also increased with warm sea surface temperatures in the NBS suggesting that prey quality and quantity during warm years is adequate to foster energy storage for the oncoming winter (Garcia and Sewall in press; Fig. 8).
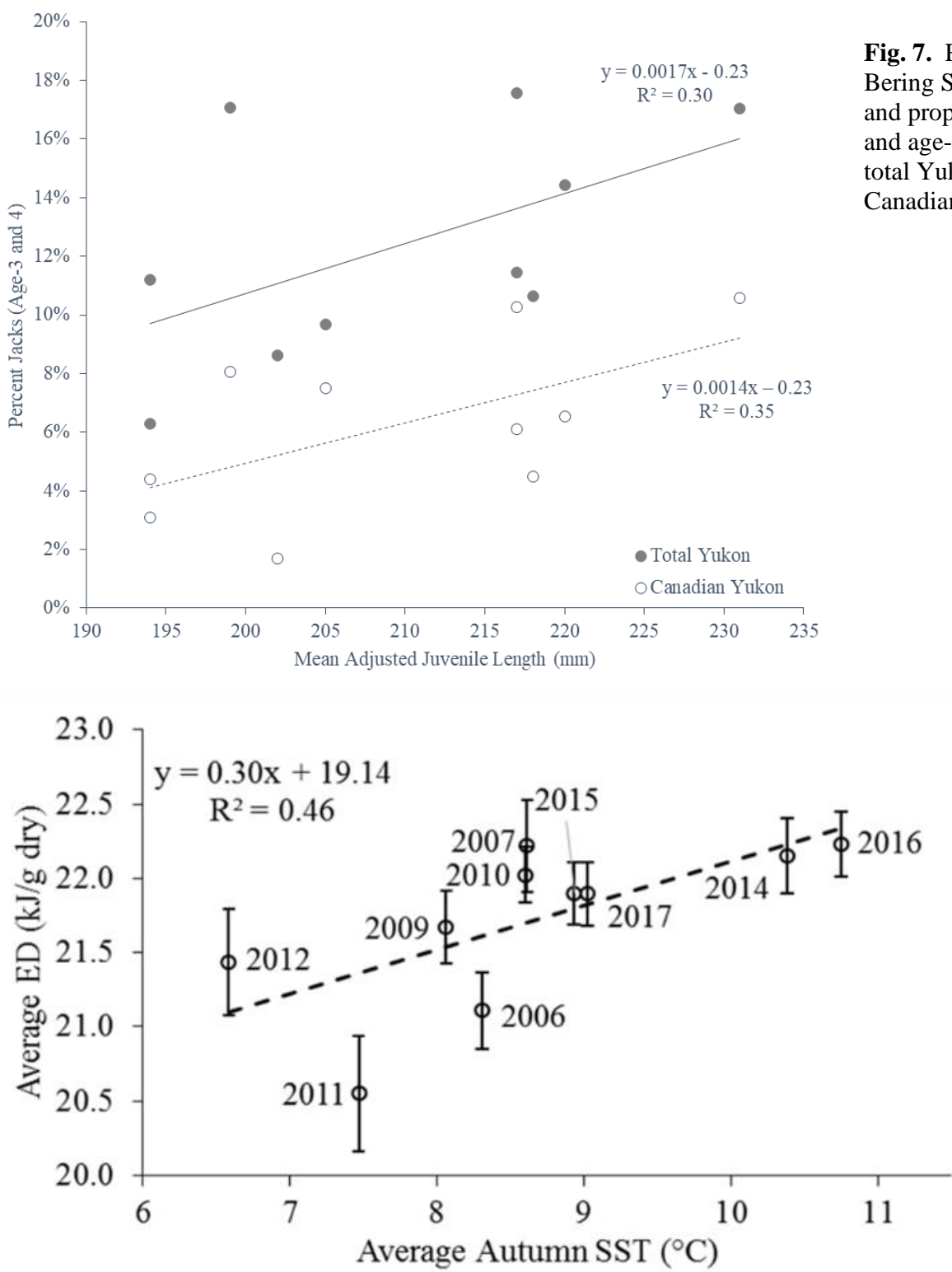

Fig. 7. Relationship between northeastern Bering Sea juvenile Chinook salmon length and proportion of adults maturing as age- 3 and age-4 ("jacks") from those cohorts for total Yukon River (black circles) and Canadian-origin (grey circles) stocks.
Fig. 8. Annual mean energy density $\left(\mathrm{ED} ; \mathrm{kJ}^{-\mathrm{g}^{-1}}\right)$ of dry tissue mass by average autumn sea surface temperature (SST) for juvenile Chinook salmon caught during surface trawl surveys in the northeastern Bering Sea (2006-2017). Simple linear regression model fit shown by dashed line ( $n=10$ years). Error bars represent $95 \%$ confidence intervals. Data unavailable for 2008 and 2013.

It is apparent from available data that conditions experienced prior to their first September at sea are highly influential to Yukon River Chinook salmon productivity, cohort strength, phenology, growth patterns, and size and age at maturity. While freshwater factors cannot be excluded from contributing to observed population patterns, 
additional work understanding the ecology of Chinook salmon in their first few weeks to months in the ocean will be critical to identifying mechanisms responsible for structuring Yukon River Chinook salmon productivity patterns. The NBS surveys have elucidated the influence of warm sea surface temperature on size, growth, diet and condition of juvenile Chinook salmon. Increases of up to $3^{\circ} \mathrm{C}$ in sea surface temperature and further reductions in sea ice are predicted for the Bering Sea in the $21^{\text {st }}$ century (Wang et al. 2012). How this predicted warming may affect juvenile Chinook salmon remains to be seen. Future NBS surveys will continue to inform fisheries management on the Yukon River and provide further evidence of how juvenile Chinook salmon will adapt to a warming Bering Sea.

\section{REFERENCES}

ADF\&G Chinook Salmon Research Team. 2013. Chinook salmon stock assessment and research plan, 2013. Alaska Department of Fish and Game, Special Publication No. 13-01, Anchorage. 62 pp.

Beamish, R.J. and C. Mahnken. 2001. A critical size and period hypothesis to explain natural regulation of salmon abundance and the linkage to climate and climate change. Prog. Oceanogr. 49: 423-437.

Estensen, J.L., S.N. Schmidt, S. Garcia, C.M. Gleason, B.M. Borba, D.M. Jallen, A.J. Padilla, and K.M. Hilton. 2015. Annual management report Yukon Area, 2014. Alaska Department of Fish and Game, Fishery Management Report No. 15-50, Anchorage. 286 pp.

Farley, Jr., E.D., J.H. Moss, and R.J. Beamish. 2007. A review of the critical size, critical period hypothesis for juvenile pacific salmon. N. Pac. Anadr. Fish Comm. Bull. 4: 311-317. (Available at https://npafc.org)

Garcia, S., and F. Sewall. In press. Diet and energy density assessment of juvenile Chinook salmon from northeastern Bering Sea trawl surveys, 2004-2017. Alaska Department of Fish and Game, Fishery Data Series, Anchorage.

Hartt, A.C. 1980. Juvenile salmonids in the oceanic ecosystem: the critical first summer. In Salmonid ecosystems of the North Pacific. Edited by W.J. McNeil and D.C. Himsworth. Oregon State University Press, Corvalis. pp. 25-57.

Howard, K.G., S. Garcia, J. Murphy, and T.H. Dann. 2019. Juvenile Chinook salmon abundance index and survey feasibility assessment in the Northern Bering Sea, 2014-2016. Alaska Department of Fish and Game, Fishery Data Series No. 19-04, Anchorage. 93 pp.

Howard, K.G., S. Garcia, J. Murphy, and T.H. Dann. In press. Northeastern Bering Sea juvenile Chinook salmon survey, 2017. Alaska Department of Fish and Game, Fishery Data Series, Anchorage.

Munro, A.R., and E.C. Volk. 2014. Summary of Pacific salmon escapement goals in Alaska with a review of escapements from 2005 to 2013. Alaska Department of Fish and Game, Fishery Manuscript Series No. 14-01, Anchorage. $121 \mathrm{pp}$.

Murphy, J.M., W.D. Templin, E.V. Farley, and J.E. Seeb. 2009. Stock-structured distribution of western Alaska and Yukon juvenile Chinook salmon (Oncorhynchus tshawytscha) from United States BASIS surveys, 20022007. N. Pac. Anadr. Fish Comm. Bull. 5: 51-59. (Available at https://npafc.org)

Murphy, J., K.G. Howard, J.C. Gann, K.C. Cieciel, W.D. Templin, and C.M. Guthrie. 2017. Juvenile Chinook salmon abundance in the northern Bering Sea: implications for future returns and fisheries in the Yukon River. Deep-Sea Res. II. 135: 156-167.

Pearcy, W.G. 1992. Ocean ecology of the North Pacific salmonids. Univ. Washington Press, Seattle. 179 pp.

Pella, J., and M. Masuda. 2001. Bayesian methods for analysis of stock mixtures from genetic characters. Fish. Bull. 99: 151-167.

Siegel, J.E., M.V. McPhee, and M.D. Adkison. 2017. Evidence that marine temperatures influence growth and maturation of western Alaskan Chinook salmon. Mar. Coast. Fish. 9: 441-456.

Wang, M., J.E. Overland, and P. Stabeno. 2012. Future climate of the Bering and Chukchi seas projected by global climate models. Deep-Sea Res. II. 65-70: 46-57. 